\title{
Emergency Department Management of Mild Traumatic Brain Injury in New Delhi-A Single Institute Cohort Management Data
}

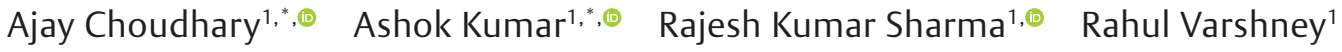 \\ Satya Shiva Munjal ${ }^{1, \odot}$ Kaviraj Kaushik ${ }^{1, \odot ~ L a x m i ~ N a r a y a n ~ G u p t a ~}{ }^{1, \odot}$
}

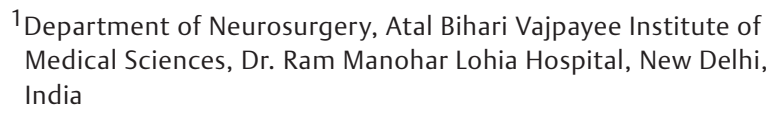

${ }^{1}$ Department of Neurosurgery, Atal Bihari Vajpayee Institute of Medical Sciences, Dr. Ram Manohar Lohia Hospital, New Delhi, India

Indian J Neurosurg 2022;11:123-127

\begin{abstract}
Address for correspondence Rajesh Kumar Sharma, MBBS, MS, MCh, Department of Neurosurgery, Atal Bihari Vajpayee Institute of Medical Sciences, Dr. Ram Manohar Lohia Hospital, New Delhi 110001, India (e-mail: drsrk22@gmail.com).
\end{abstract}

\begin{abstract}
Keywords

- mild traumatic brain injury

- emergency care

- clinical management

Introduction The purpose of this study is to compare the current clinical management practices and decision guidelines of the Brain Trauma Foundation (BTF) for mild traumatic brain insult with line of treatment followed at our center to identify the clinically significant treatment outcome in pediatric to elderly patients.

Materials and Methods This is a questionnaire-based prospective observational study at the emergency department of neurosurgery in Dr. Ram Manohar Lohia (RML) Hospital, New Delhi. A registry questionnaire was administered to all the eligible subjects by the neurosurgery resident in emergency department (ED) to correlate clinical status, severity of traumatic brain injury (TBI) and associated comorbid conditions and its outcome after management.

Results Out of 154 mild TBI cases attending ED, 115 (74.7\%) were males and 39 (25.3\%) were females, with average age of 27 years. Of the patients with mild TBI, road traffic accidents (RTA) were the main cause (50.6\%), followed by fall from height (42.9\%), assault and sports-related injury (6.4\%). Of the total, $96.1 \%$ underwent CT. Of these, $31.8 \%$ found abnormal CT results, $27.5 \%$ received wound treatment care, and $9.1 \%$ received emergency care. Nearly $30.5 \%$ were admitted and $1.3 \%$ patients were died in the hospital, $75.3 \%$ patients were discharged and $23.4 \%$ were referred to other department for associated co morbid conditions.

Conclusion The present study identified deficiencies in and variation around several important aspects of ED care. The development of BTF guidelines specific for mild TBI could reduce variation and improve emergency care for this injury.
\end{abstract}

\section{Introduction}

Glasgow coma scale (GCS) score of 13 to 15 is indicative of mild traumatic brain injury (TBI) with clinical symptoms of loss of consciousness (LOC), amnesia or peri-injury disorientation. Approximately, 70 to $90 \%$ of extra and intracranial insults that occur worldwide are diagnosed as mild TBI. ${ }^{1,2}$ The

* Both authors contributed equally to this work.

published online

March 11, 2021
DOI https://doi.org/ $10.1055 / \mathrm{s}-0040-1719236$ ISSN 2277-954X.
World Health Organization (WHO) in the year 1997 suggested the significance of research efforts to cut down the consequences of mild TBI. ${ }^{3}$

According to the National Institute of Health, mild TBI is a leading public health condition, and efforts should be made to diminish the rate of disability after a mild TBI. These efforts should be a national research priority. ${ }^{4}$ As much as $5 \%$ of 
patients with so-called "mild" TBI depict traumatic abnormalities on initial head CT scan, with $1 \%$ requiring neurosurgical intervention in the acute stage of injury. ${ }^{5}$ Disability after mild traumatic brain insult occurs due to cognitive, physical, psychological, and social impairment and results in significant malady and redundancy. ${ }^{4,6,7}$ As far as $50 \%$ of patients with mild TBI are affected by postconcussion symptoms after 1 month of injury and 15 to $20 \%$ at 1 -year duration. ${ }^{89}$ The emergency department (ED) is the "shop window" of any hospital. It is the most critical and life-saving area, providing urgent care to critically ill patients. In the case of mild TBI care, ED is an important component of the hospital; albeit, the most overlooked. Although the ED is the fulcrum for most of the patients with mild TBI, its management in the ED has not been described. Since the follow-up rate of these patients is quite low, therefore their only contact with the medical system is the ED. ${ }^{10}$

Currently, there are no mild TBI specific therapies; the diagnostics and line of management administered to the patient have the potential to affect the outcome. ${ }^{11,12}$ The clinical management of these patients is variable, and despite the availability of the clinical guidelines, the majority of patients will undergo CT imaging and most of the interpretation is normal. ${ }^{13}$

If the patient is directly referred to the neuropsychological specialists, once they are discharged from the ED, it reduces the long-term cognitive disability. ${ }^{14,15}$ Serotonin reuptake inhibitors and benzodiazepines are given soon after the injuries have been known to reduce postconcussion symptoms after mild TBI. ${ }^{16}$ For good recovery outcome after mild TBI, identification of lacunae in the care and complete description of the ED are considered the initial vital steps in the care of mild traumatic brain insult.

A wide range of variations in some aspects of emergency care has been reported in the case of mild TBI. Several centers in Europe and Canada have described variations in the use of CT after a mild TBI. ${ }^{15-18}$ In countries like Sweden and Norway, a disparity of $15 \%$ to $94 \%$ has been reported in the hospital admission rates for mild TBI. ${ }^{13,16,17}$

The main objective of this study is to describe the emergency management plan in the ED of Dr. Ram Manohar Lohia Hospital (RML) Hospital, New Delhi, for mild TBI. We sought to identify the lacunae in the care around ED for mild TBI cases to determine the specific guidelines for its management.

\section{Materials and Methods}

This study was approved by the ethics committee of Atal Bihari Vajpayee Institute of Medical Sciences and RML Hospital (no-176(45/2016) IEC/PGIMER/RMLH), and consent for participation was obtained from each participant enrolled in this study. The study included all the patients with trauma, having clinical/radiological evidence of head injury alone or in association with other injuries admitted in the ED of RML Hospital, New Delhi, for one year (June 2017 to June 2018).

A questionnaire was administered to each participant by the neurosurgery resident on call in the ED. The form included details like patient demographics, cause of injury, clinical history, Glasgow coma score (GCS) on arrival to the study center, prehospital care, clinical findings, neurological examination, and radiological findings. The severity of TBI was diagnosed according to the GCS score. Early CT scan was done to understand the type of injury to administer the appropriate line of treatment. The progress and outcome in the ED room were recorded by neurology examination. GCS was used for the age group more than 5 years, and the pediatric coma scale (by Simpson and Reilly) was used for pediatric age group less than 5-year cases. Based on GCS, TBI cases were graded as mild (13-15), moderate (9-12) and severe $(<8)$.

\section{Data Analysis}

Statically analysis was performed using statistical software SPSS version 17. The data were presented as no. (\%) and median (interquartile ranges). All analysis was performed at the $95 \%$ confidence interval.

\section{Result}

A total of 154 patients of mild head injury attended the neurosurgery ED of RML Hospital during 2017-2018. The median ages of patients attended were 27 years ( - Table $\mathbf{1}$ ).

There were 115 (74.7\%) males and 39 (25.3\%) females. Most of the patients were healthy 141 (91.6\%) with mild systemic diseases 13 (8.4\%) before the injury happened. Of the patients with mild TBI, predominant mode of TBI was road traffic accidents (RTA) (50.6\%), followed by fall from height (42.9\%), assault and sports-related injury (6.4\%). Of the total, 92.9\% were from blunt injury, and injury at outermost were absent in $7.1 \%$ of patients. Most of the injuries occurred while at home and were accidental (40.9\%) and were directly referred $(83.1 \%)$ from the primary center (-Table $\mathbf{1}$ ).

First aid for pain management was provided by trained personnel (doctors/paramedics) in $27.5 \%$ cases only and no care was provided in the rest of the cases (72.5\%) (-Table 2). The events following the injury included episode of loss of consciousness (LOC) in $7.1 \%$ cases, vomiting in $3.95 \%$ cases, LOC with ear nose throat (ENT) bleed in $0.6 \%$, and LOC with vomiting in 19.5 cases. The rest (68.8\%) of the patients presented with no history of event after injury. On examination, $5.9 \%$ cases had abnormal pupillary response, but in $94.1 \%$ patients, pupillary responses were found normal. The majority $(46.8 \%)$ of TBI cases showed some form of upper body injury on head/face and neck region, and $46.1 \%$ cases showed upper body injury on cervical, pelvic and lower limb skin lesions (-Table 3).

On radiological examinations, $96.1 \%$ of patients with mild brain injury underwent CT scan, in which $54.1 \%$ were done between 2 to 4 hours after attending the ED room and $45.9 \%$ were performed between 4 to 6 hours. On CT scan of head, $31.8 \%$ of cases revealed abnormal findings; however, all of these patients were given conservative treatment and discharged later ( - Table 4).

On the basis of clinical examination, average median GCS score of all attending mild TBI patients were 14 , while blood pressure and spo2 level at the ED room during clinical assessments were found to be normal (-Table 5). The patients were brought to hospital mainly by people 
A Cohort Emergency Management Data of Mild Traumatic Brain Injury Choudhary et al. 125

Table 1 Demographic characteristics of the patients

\begin{tabular}{|c|c|c|}
\hline $\begin{array}{l}\text { Demographic } \\
\text { characteristics }\end{array}$ & Frequency $(n)$ & Percent (\%) \\
\hline $\begin{array}{l}\text { Age (years, median } \\
\text { range) }\end{array}$ & $27(18-38)$ & \\
\hline \multicolumn{3}{|l|}{ Gender } \\
\hline Female & 39 & 25.3 \\
\hline Male & 115 & 74.7 \\
\hline \multicolumn{3}{|l|}{ Preinjury condition } \\
\hline A normal healthy & 141 & 91.6 \\
\hline $\begin{array}{l}\text { A patient with mild } \\
\text { systemic disease }\end{array}$ & 13 & 8.4 \\
\hline \multicolumn{3}{|l|}{ Mechanism of injury } \\
\hline Assault & 5 & 3.2 \\
\hline Fall from height & 66 & 42.9 \\
\hline RTA & 78 & 50.6 \\
\hline Sports-related injury & 5 & 3.2 \\
\hline \multicolumn{3}{|l|}{ Type of injury } \\
\hline Blunt & 143 & 92.9 \\
\hline Outermost absent & 11 & 7.1 \\
\hline \multicolumn{3}{|l|}{ Location of incident } \\
\hline $\begin{array}{l}\text { On pedestrian near } \\
\text { home }\end{array}$ & 63 & 40.9 \\
\hline $\begin{array}{l}\text { Other, please specify } \\
\text { Fall from train }\end{array}$ & 1 & 0.6 \\
\hline Public place & 4 & 2.6 \\
\hline Street & 4 & 2.6 \\
\hline Street/traffic & 81 & 52.6 \\
\hline Workplace & 1 & 0.6 \\
\hline \multicolumn{3}{|l|}{ Referral condition } \\
\hline Primary referral & 128 & 83.1 \\
\hline $\begin{array}{l}\text { Secondary referral } \\
\text { from other hospital }\end{array}$ & 26 & 16.9 \\
\hline
\end{tabular}

Abbreviation: RTA, road traffic accident.

Note: Table values represent as number of participants in frequency $(n)$, percentage (\%) and median (iqr).

known to them with no professional care 124 (80.5\%), and only a few $(30,19.4 \%)$ cases were accompanied by medical and ambulance vans. In suspected polytrauma cases, radiological evaluation of other body parts was also done, and evidence of injury was noted in $37 \%$ cases, of which $1.3 \%$ cases expired ( $\mathbf{- T a b l e ~} \mathbf{2}$ ).

\section{Disposition}

The disposition of patients with mild TBI is shown in - Table 2. Most of them were discharged with instructions to follow-up with the referring doctor or were referred to another, unspecified doctor or clinic. However, approximately $37.2 \%$ of patients with isolated mild TBI per year were instructed either to return to the ED "as needed" or not undergo any follow-up at all.
Table 2 Types of care provided, and treatment given in ER.

\begin{tabular}{|c|c|c|}
\hline & Frequency $(n)$ & Percent (\%) \\
\hline \multicolumn{3}{|l|}{$\begin{array}{l}\text { Care provided to reach } \\
\text { hospital }\end{array}$} \\
\hline Ambulance service & 21 & 13.6 \\
\hline Medical mobile team & 9 & 5.8 \\
\hline No professional care & 124 & 80.5 \\
\hline \multicolumn{3}{|l|}{ Emergency care in ED } \\
\hline No & 140 & 90.9 \\
\hline Yes & 14 & 9.1 \\
\hline \multicolumn{3}{|l|}{ Pain treatment given in ED } \\
\hline No & 111 & 72.5 \\
\hline Yes & 42 & 27.5 \\
\hline \multicolumn{3}{|l|}{ Admission in hospital } \\
\hline No & 107 & 69.5 \\
\hline Yes & 47 & 30.5 \\
\hline \multicolumn{3}{|l|}{ Status on discharge } \\
\hline Dead & 2 & 1.3 \\
\hline Discharged home & 116 & 75.3 \\
\hline $\begin{array}{l}\text { Refer to other depart- } \\
\text { ment for other } \\
\text { comorbidities }\end{array}$ & 36 & 23.4 \\
\hline
\end{tabular}

Abbreviation: ED, emergency department.

Note: Table values represent as number of participants in frequency $(n)$, percentage (\%).

Table 3 Clinical history related to injury

\begin{tabular}{|l|l|l|}
\hline Clinical history & Frequency $(\boldsymbol{n})$ & Percent (\%) \\
\hline Sensorium after injury & & \\
\hline LOC & 11 & 7.1 \\
\hline Vomiting & 6 & 3.9 \\
\hline LOC, ENT bleed & 1 & 0.6 \\
\hline LOC, vomiting & 30 & 19.5 \\
\hline No history & 106 & 68.8 \\
\hline Pupils & 144 & 94.1 \\
\hline Both reacting & 1 & 0.7 \\
\hline Left pupil reacting & 4 & 2.6 \\
\hline None reacting & 4 & 2.6 \\
\hline $\begin{array}{l}\text { Right pupils' } \\
\text { dilatation }\end{array}$ & 3 & 1.9 \\
\hline $\begin{array}{l}\text { Upper body } \\
\text { abnormality }\end{array}$ & 28 & 1.3 \\
\hline Brain injury & 3 & 2.6 \\
\hline $\begin{array}{l}\text { Brain injury with } \\
\text { face injury }\end{array}$ & 2 & 1.9 \\
\hline $\begin{array}{l}\text { Face injury } \\
\text { Head with neck, face } \\
\text { injury }\end{array}$ & 4 & \\
\hline $\begin{array}{l}\text { Head and neck } \\
\text { injury }\end{array}$ & 3 & \\
\hline
\end{tabular}

(Continued) 
Table 3 (Continued)

\begin{tabular}{|l|l|l|}
\hline Clinical history & Frequency $(\mathbf{n})$ & Percent (\%) \\
\hline $\begin{array}{l}\text { Brain injury with } \\
\text { neck injury }\end{array}$ & 32 & 20.8 \\
\hline No injury & 82 & 53.2 \\
\hline $\begin{array}{l}\text { Lower body } \\
\text { abnormality }\end{array}$ & 11 & 7.1 \\
\hline $\begin{array}{l}\text { Abdomen/pelvic } \\
\text { girdle pain }\end{array}$ & 18 & 11.7 \\
\hline Cervical pain & 17 & 11.0 \\
\hline $\begin{array}{l}\text { External skin lesions } \\
\text { Wound on lower } \\
\text { limbs }\end{array}$ & 3 & 7.9 \\
\hline $\begin{array}{l}\text { Lower extremities } \\
\text { pain }\end{array}$ & 11 & 7.1 \\
\hline $\begin{array}{l}\text { Lower extremities/ } \\
\text { external skin wound }\end{array}$ & 11 & 53.9 \\
\hline No abnormality & 83 & 7.9 \\
\hline
\end{tabular}

Abbreviations: ENT, eye nose throat; LOC, loss of consciousness. Note: Table values represent as number of participants in frequency (n), percentage (\%).

Table 4 CT examination for mild TBI

\begin{tabular}{|c|l|l|}
\hline & Frequency $(\boldsymbol{n})$ & Percent (\%) \\
\hline CT procedure & & \\
\hline Not performed & 6 & 3.9 \\
\hline Performed & 148 & 96.1 \\
\hline $\begin{array}{l}\text { CT time after } \\
\text { attending in ED }\end{array}$ & & \\
\hline Between 2 to 4 hours & 80 & 54.1 \\
\hline Between 4 to 6 hours & 68 & 45.9 \\
\hline CT findings & & 31.8 \\
\hline Abnormal & 47 & 68.2 \\
\hline Normal & 101 & \\
\hline
\end{tabular}

Abbreviations: CT, computed tomography; ED, emergency department, TBI, traumatic brain injury.

Note: Table values represent as number of participants in frequency ( $n)$, percentage (\%).

Table 5 Clinical examination of the patients

\begin{tabular}{|l|l|}
\hline Clinical examination & Median $(\boldsymbol{n}=$ range) \\
\hline GCS at the time of arrival & $14(13-15)$ \\
\hline $\begin{array}{l}\text { Systolic blood pressure at } \\
\text { arrival (mm Hg) }\end{array}$ & $120(110-130)$ \\
\hline $\begin{array}{l}\text { Diastolic blood pressure } \\
\text { arrival (mm Hg) }\end{array}$ & $74(70-80)$ \\
\hline Spo2 level at arrival $(\mathrm{mm} \mathrm{Hg})$ & $100(98-100)$ \\
\hline
\end{tabular}

Abbreviations: GCS, Glasgow coma score; Spo2, peripheral capillary oxygen saturation.

Note: Table values represent as number of participants in frequency ( $n)$, percentage (\%).

\section{Variation in ED Care for Mild TBI}

Of the 154 patients, 34 patients were care variables, and we were unable to analyze 15 , because too few patients received them. These variables were MRI scan, blood alcohol level, admitted to intensive care unit, left ED without being seen by a doctor, and triaged out of the ED. The geographical region and increasing age were supposed to be a significant independent predictors of receiving analgesics for pain in the ED and receiving other blood tests (that is, a blood test other than a full blood count or blood alcohol level). This is not mentioned in the table.

\section{Discussion}

This study demonstrated that substantial ED resources are dedicated to the care of mild TBI patients. On an average per year, over 2000 patients with mild TBI underwent CT, apparently of the head and brain, and a nonextremity, nonchest X-ray, such as that of a skull or cervical spine, for over 500 patients.

There are many teething problems and lacunae which have been identified in the ED care for isolated mild traumatic brain insults. These include improper documentation such as that of pain score, less than $44 \%$ of patients had pain score documented in their records. Since headache is thought to be a prime contributing symptom of postconcussion syndrome and considered a primary cause of long-term disability and morbidity after a mild TBI, therefore, accurate pain score documentation is a necessary mandate and is of utmost significance. Since 2000, routine assessment of pain is necessary and required in all the hospitals to be accredited. ${ }^{19}$

The present data of our study precedes the release of these standard protocols; efforts to ameliorate the documentation process should be continued as a quality improvement measure in the EDS that provide care to the patients with mild TBI. Only $27.5 \%$ of patients with documented pain score received a dose of analgesia. Substandard treatment of pain in the ED, especially among children, has been reported by others. ${ }^{20,21}$

Postmild TBI headache is known to be treatable with a wide range of therapeutic agents, from nonsteroidal anti-inflammatory drugs (NSAIDS) to dihydroergotamine. ${ }^{16}$ Aftereffects of early analgesic use on long-term outcome after a TBI is not known, and it would be a fruitful area for future investigation. 1200 patients with isolated mild TBI per year were discharged from EDs without any recommendation for any specific follow-up. Some of the patients were asked to turn up to the ED only when needed. On the other hand, the rest were told not to come up to the ED as they do not need any follow-up sessions. ${ }^{22}$

There are very few referral centers in New Delhi for the evaluation of mild TBI, which may partially responsible for such findings. According to a survey of 68 levels, one trauma center in the US, only $35 \%$ of referred patients with mild TBI turn up for follow-up evaluation after being discharged from ED (22). Since the patient may experience postconcussion symptoms even after 1 year of mild TBI, therefore follow-up care is of utmost significance. ${ }^{9-12,23}$ 
In two randomized controlled trials, routine follow-up was shown to diminish the severity and the number of symptoms occurring postconcussion after a mild traumatic insult. ${ }^{14,15}$ The Medical Disability Society in Britain recommended routine follow-up for all TBI patients. However, no such protocol exists in India. Across ages, there are several lacunae identified in the ED management of TBI. ${ }^{24}$ For younger patients, the frequency of analgesic administration and blood testing is quite less due to the high-tendency of vomiting postconcussion and also because of a belief held by parents and healthcare givers that analgesics may cause unwanted effects and mask other specific symptoms. Exploring the barriers to the administration of analgesics in the case of a mild TBI would surely be an important area of future research works.

\section{Limitations of the Study}

Other limitations include data documentation. Since data are extracted from ED charts after care is delivered, it is most of the time cumbersome to differentiate a care item not performed from the one which is administered but not documented in the pro forma.

\section{Conclusion}

Substantial ED resources are prerequisites for the care of mild TBI in the ED. However, the current study identified a plethora of deficiencies in the care plan. Many patients were discharged without any specific discharge advice and recommendations. Pain, an important symptom, was unreported and undertreated. Documentation errors were found in many of the ED records. There were several other parameters such as delayed initial CT scan, incomplete history recording, documentation of a case as medicolegal or nonmedicolegal. All these findings suggest that there is a need for the development of guidelines specific for mild TBI care in the ED.

\section{Conflict of Interest}

None declared.

\section{Acknowledgment}

The authors sincerely appreciate the efforts of the residents of the neurosurgery department and the trauma care staff for their kind help and cooperation in completing this study.

\section{References}

1 Jager TE, Weiss HB, Coben JH, Pepe PE. Traumatic brain injuries evaluated in U.S. emergency departments, 1992-1994. Acad Emerg Med 2000;7(2):134-140

2 Centers for Disease Control and Prevention. National Center for Injury Prevention and Control. Report to Congress. Mild Traumatic Brain Injury in the United States: Steps to Prevent a Serious Public Health Problem. Atlanta, GA: Centers for Disease Control and Prevention, 2003

3 von Holst H, Cassidy JD. Mandate of the WHO Collaborating Centre Task Force on Mild Traumatic Brain Injury. J Rehabil Med 2004;43(43, Suppl):8-10
4 National Institutes of Health. NIH Consensus Development Panel on Rehabilitation of Persons with Traumatic Brain Injury. JAMA 1999;282:974-983

5 Jagoda AS, Cantrill SV, Wears RL, et al; American College of Emergency Physicians. Clinical policy: neuroimaging and decisionmaking in adult mild traumatic brain injury in the acute setting. Ann Emerg Med 2002;40(2):231-249

6 Jorge RE, Robinson RG, Starkstein SE, Arndt SV. Influence of major depression on 1-year outcome in patients with traumatic brain injury. J Neurosurg 1994;81(5):726-733

7 Bazarian JJ, Atabaki S. Predicting postconcussion syndrome after minor traumatic brain injury. Acad Emerg Med 2001;8(8):788-795

8 Jay GW, Goka RS, Arakaki AH. Minor traumatic brain injury: review of clinical data and appropriate evaluation and treatment. J Insur Med 1996;27(4):262-282

9 Bazarian JJ, Wong T, Harris M, Leahey N, Mookerjee S, Dombovy M. Epidemiology and predictors of post-concussive syndrome after minor head injury in an emergency population. Brain Inj 1999;13(3):173-189

10 Bazarian J, Hartman M, Delahunta E. Minor head injury: predicting follow-up after discharge from the emergency department. Brain Inj 2000;14(3):285-294

11 Levin HS, Mattis S, Ruff RM, et al. Neurobehavioral outcome following minor head injury: a three-center study. J Neurosurg 1987;66(2):234-243

12 Carroll LJ, Cassidy JD, Peloso PM, et al; WHO Collaborating Centre Task Force on Mild Traumatic Brain Injury. Prognosis for mild traumatic brain injury: results of the WHO Collaborating Centre Task Force on Mild Traumatic Brain Injury. J Rehabil Med 2004;43(43, Suppl):84-105

13 Seelig JM, Becker DP, Miller JD, Greenberg RP, Ward JD, Choi SC. Traumatic acute subdural hematoma: major mortality reduction in comatose patients treated within four hours. N Engl J Med 1981;304(25):1511-1518

14 Ponsford J, Willmott C, Rothwell A, et al. Impact of early intervention on outcome after mild traumatic brain injury in children. Pediatrics 2001;108(6):1297-1303

15 Wade DT, King NS, Wenden FJ, Crawford S, Caldwell FE. Routine follow up after head injury: a second randomised controlled trial. J Neurol Neurosurg Psychiatry 1998;65(2):177-183

16 Mittenberg W, Canyock EM, Condit D, Patton C. Treatment of post-concussion syndrome following mild head injury. J Clin Exp Neuropsychol 2001;23(6):829-836

17 Klassen TP, Reed MH, Stiell IG, et al. Variation in utilization of computed tomography scanning for the investigation of minor head trauma in children: a Canadian experience. Acad Emerg Med 2000;7(7):739-744

18 Stiell IG, Wells GA, Vandemheen K, et al. Variation in ED use of computed tomography for patients with minor head injury. Ann Emerg Med 1997;30(1):14-22

19 Phillips DM; Joint Commission on Accreditation of Healthcare Organizations. JCAHO pain management standards are unveiled. JAMA 2000;284(4):428-429

20 Guru V, Dubinsky I. The patient vs. caregiver perception of acute pain in the emergency department. J Emerg Med 2000;18(1):7-12

21 Petrack EM, Christopher NC, Kriwinsky J. Pain management in the emergency department: patterns of analgesic utilization. Pediatrics 1997;99(5):711-714

22 Blostein P, Jones SJ. Identification and evaluation of patients with mild traumatic brain injury: results of a national survey of level I trauma centers. J Trauma 2003;55(3):450-453

23 Borczuk P. Mild head trauma. Emerg Med Clin North Am 1997;15(3):563-579

24 Chambers J, Cohen SS, Hemminger L, Prall JA, Nichols JS. Mild traumatic brain injuries in low-risk trauma patients. J Trauma 1996;41(6):976-980 